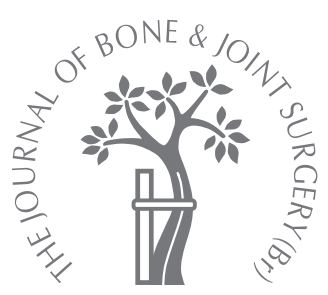

S. Dimmen,

L. Nordsletten,

L. Engebretsen,

H. Steen,

J. E. Madsen

From Ullevaal

University Hospital,

Oslo, Norway

\title{
The effect of parecoxib and indometacin on tendon-to-bone healing in a bone tunnel
}

\author{
AN EXPERIMENTAL STUDY IN RATS
}

들 S. Dimmen, MD, Orthopaedic

Surgeon

L. Nordsletten, MD, PhD,

Professor

ㅁ. L. Engebretsen, MD, PhD,

Professor

II. J. Madsen, MD, PhD,

Professor

Orthopaedic Centre

Ullevaal University Hospital

and Faculty of Medicine,

University of Oslo, $\mathrm{N}-0407$

Oslo, Norway.

H. Steen, MD, PhD

Orthopaedic Surgeon

Institute for Surgical Research

Rikshospitalet-

Radiumhospitalet Medical

Centre and Faculty of Medicine,

University of Oslo, $\mathrm{N}-0027$

Oslo, Norway.

Correspondence should be sent to Dr S. Dimmen; e-mail:

sidimmen@online.no

(C)2009 British Editorial Society

of Bone and Joint Surgery

doi:10.1302/0301-620X.91B2

$21471 \$ 2.00$

$J$ Bone Joint Surg [Br]

2009;91-B:259-63.

Received 27 June 2008;

Accepted after revision 16

October 2008

Conventional non-steroidal anti-inflammatory drugs (NSAIDs) and newer specific cyclooxygenase-2 (cox-2) inhibitors are commonly used in musculoskeletal trauma and orthopaedic surgery to reduce the inflammatory response and pain. These drugs have been reported to impair bone metabolism. In reconstruction of the anterior cruciate ligament the hamstring tendons are mainly used as the graft of choice, and a prerequisite for good results is healing of the tendons in the bone tunnel. Many of these patients are routinely given NSAIDs or cox-2 inhibitors, although no studies have elucidated the effects of these drugs on tendon healing in the bone tunnel.

In our study 60 female Wistar rats were randomly allocated into three groups of 20 . One received parecoxib, one indometacin and one acted as a control. In all the rats the tendoAchillis was released proximally from the calf muscles. It was then pulled through a drill hole in the distal tibia and sutured anteriorly. The rats were given parecoxib, indometacin or saline intraperitoneally twice daily for seven days. After 14 days the tendon/bone-tunnel interface was subjected to mechanical testing.

Significantly lower maximum pull-out strength $(p<0.001)$, energy absorption $(p<0.001)$ and stiffness $(p=0.035)$ were found in rats given parecoxib and indometacin compared with the control group, most pronounced with parecoxib.

Rupture of the anterior cruciate ligament (ACL) is a common injury in athletic or recreational activities with an incidence of 85/ 100000 in the age group of 16 to 39 years. $^{1}$ Reconstruction using grafts of semitendinosus and gracilis has become increasingly popular and has produced similar results to those of the bone-patellar tendon-bone-graft procedures. $^{2-4}$ These and other tendons are also widely used in ligament reconstructions in general. In order to achieve the best possible post-operative stability, solid healing between the tendon and bone is essential when utilising these grafts. ${ }^{5}$

Non-steroidal anti-inflammatory drugs (NSAIDs), conventional cyclo-oxygenase (cox) inhibitors and the specific cox-2 inhibitors are commonly used in musculoskeletal trauma and orthopaedic surgery to reduce inflammation and pain. Conventional cox inhibitors impair the healing of fractures ${ }^{6-10}$ and recent studies have detected similar findings with cox-2 inhibitors. ${ }^{11-13}$ This study was designed to investigate the effects of the shortterm administration of indometacin, a conventional cox inhibitor, and parecoxib, a selective cox-2 inhibitor, on tendon-to-bone healing. Our hypothesis was that the drugs would decrease the tendon-to-bone failure strength.

\section{Materials and Methods}

We randomly allocated 60 female Wistar rats (Taconic Europe, Lille Skensved, Denmark) with a mean weight of $241 \mathrm{~g}$ (212 to 268) into three groups of 20 . One group received parecoxib, one indometacin and there was one control group. The rats were kept in pairs in wiretopped plastic cages with free access to tap water and standard laboratory rodent food (with $1.1 \%$ calcium, $0.8 \%$ phosphorus and $1500 \mathrm{IU} / \mathrm{kg}$ of vitamin $\mathrm{D}_{3}$ ) in a 12-hour light and 12-hour dark cycle. For the operation the rats were anaesthetised with a combination of Hypnorm (fluanisone $5 \mathrm{mg} / \mathrm{ml}$, fentanyl citrate $0.1575 \mathrm{mg} / \mathrm{ml}$; Jansen Pharmaceutica BV, Beerse, Belgium) and Dormicum (midazolam $2.5 \mathrm{mg} / \mathrm{ml}$; Hoffmann La Roche, Basel, Switzerland) administered subcutaneously in a dose of $0.2 \mathrm{ml} / 100 \mathrm{~g}$ body-weight. Temgesic (buprenorphin $0.3 \mathrm{mg} / \mathrm{ml}$; Schering-Plough, Kenilworth, New Jersey) in a dosage of $0.005 \mathrm{mg} / 100 \mathrm{~g}$ body-weight was given subcutaneously immediately post-operatively and twice per day on the 


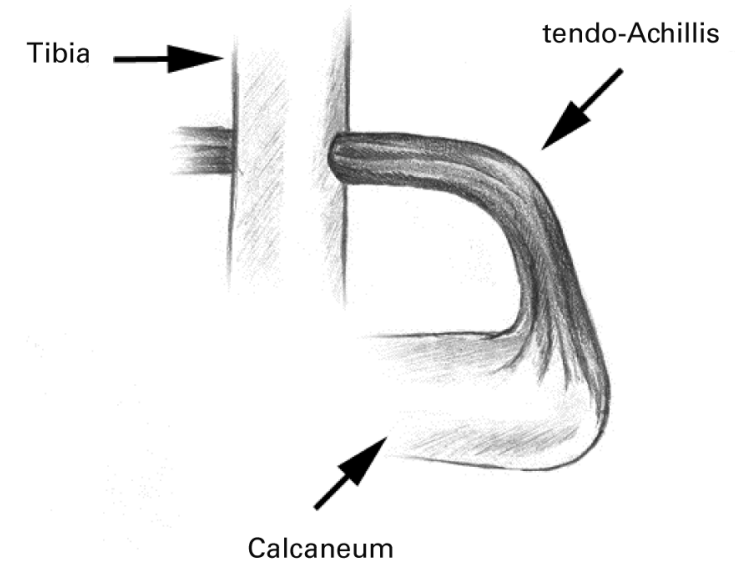

Fig. 1

Diagram showing the operative technique. The tendo-Achillis was pulled through a drill hole in the distal tibia.

first two days after the operation. The experiments conformed to the Norwegian Council of Animal Research Code for the Care and Use of Animals for Experimental Purposes.

Operative technique. After shaving and aseptic washing of the surgical field, an incision was made over the tendoAchillis which was then released from the calf muscles proximally. The calcaneal insertion was kept intact as was the tendon of plantaris. A drill hole $2 \mathrm{~mm}$ in diameter was then made in a posterior to anterior direction in the distal tibia approximately $3 \mathrm{~mm}$ above the ankle (Fig. 1). The tendon was pulled through the drill hole and secured anteriorly to the periosteum with a suture with the ankle held at $90^{\circ}$. The skin incision was closed with two sutures. No immobilisation was applied and the rats were allowed full weight-bearing.

Drug administration. The rats in the parecoxib group were given Dynastat (parecoxib; Pfizer, Pharmacia Europe EEIG, High Wycombe, United Kingdom) in a dosage of $0.05 \mathrm{mg} / 100 \mathrm{~g}$ body-weight intraperitoneally twice daily for seven days, the first injection being immediately before surgery. The rats in the indometacin group received Confortid (indometacin; Dumex-Alpharma A/S, Copenhagen, Denmark) in a dosage of $0.0625 \mathrm{mg} / 100 \mathrm{~g}$ body-weight and those in the control group had a corresponding volume of saline injected intraperitoneally twice daily at the same time points. The doses for parecoxib and indometacin were equivalent to those recommended for human use. No antibiotic prophylaxis was given.

Tissue processing. The rats were killed by an overdose of pentobarbital (pentobarbitalnatrium vet, $100 \mathrm{mg} / \mathrm{ml}$; Norsk Medicinaldepot, Oslo, Norway) after 14 days. The time for terminating the experiment was based on a pilot study in which we registered good healing and conditions for soft-

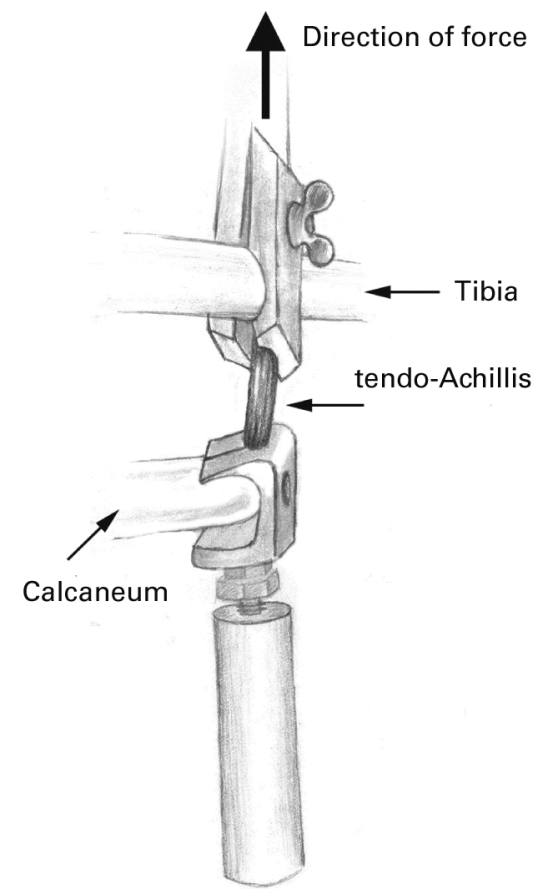

Fig. 2

Diagram showing the apparatus for mechanical testing. The tibia was fixed in a clamp and the calcaneum in a claw. The tendon was pulled straight out by a force applied aligned with the drill hole.

tissue dissection after 14 days. In a rabbit model, Liu et $\mathrm{al}^{14}$ also demonstrated secure attachment of a tendon in a bone tunnel after two weeks. The tendons were meticulously dissected free, released from the periosteum and scar tissue posteriorly and cut flush with the bone anteriorly. The only remaining contact between the tendon and the tibia was the wall of the channel inside the drill hole. The calcaneum and the insertion of the tendon were kept intact. In two rats from each group improper healing of the tendon in the bone tunnel, with the tendons slipping out during dissection, resulted in their exclusion from the study. The specimens were immersed in Ringer-acetate solution (Fresenius Kabi, Oslo, Norway) and frozen at $-20^{\circ} \mathrm{C}$ until additional processing took place. ${ }^{15}$

Mechanical testing. The tibiae were thawed in Ringeracetate solution (Fresenius Kabi). Each specimen was then loaded until pull-out in an MTS machine (Model 858 Mini Bionix with Test Star II controller; MTS Systems, Corporation Eden Prairie, Minnesota) with the tibia fixed in a clamp and with a claw around the calcaneum (Fig. 2). The force applied was aligned with the drill hole with the tendon pulled straight and with no angulation at a constant rate of $0.1 \mathrm{~mm} / \mathrm{s}$. The ultimate pull-out force, the ultimate energy absorption, the pull-out stiffness and deflection were recorded on TestStar II software (MTS Systems) and then calculated in Microsoft Excel software 
Table I. The results (mean, SD) of the tendon pull-out from the bone tunnel

\begin{tabular}{lllll}
\hline & Pull-out strength (N) & Energy absorption (Nmm) & Stiffness (N/mm) & Deflection (mm) \\
\hline Parecoxib $(\mathrm{n}=17)$ & $1.71(0.80)$ & $2.38(1.81)$ & $0.63(0.41)$ & $2.93(0.90)$ \\
Indometacin $(\mathrm{n}=17)$ & $2.25(1.14)$ & $3.22(2.07)$ & $0.73(0.44)$ & $3.31(1.27)$ \\
Control $(\mathrm{n}=14)$ (mean) & $3.52(1.09)$ & $6.46(3.27)$ & $1.02(0.39)$ & $3.58(1.00)$ \\
p-value & $<0.001$ & $<0.0001$ & 0.035 & 0.24 \\
\hline
\end{tabular}

Table II. Mean (95\% confidence interval) differences of the pull-test in the different treatment groups

\begin{tabular}{llllll}
\hline & Pull-out strength (N) & Energy absorption (Nmm) & Stiffness (N/mm) & Deflection (mm) \\
\hline Control vs parecoxib & $1.81^{*}(0.88$ to 2.73$)$ & $4.08^{*}(1.89$ to 6.27$)$ & $0.39^{*}(0.01$ to 0.77$)$ & $0.65(-0.33$ to 1.62$)$ \\
Control vs indometacin & $1.27^{*}(0.35$ to 2.20$)$ & $3.23^{*}(1.04$ to 5.43$)$ & $0.29(-0.09$ to 0.67$)$ & $0.27(-0.71$ to 1.24$)$ \\
Indometacin $v s$ parecoxib & $0.54(-0.35$ to 1.42$)$ & $0.84(-1.24$ to 2.93$)$ & $0.10(-0.26$ to 0.46$)$ & $0.38(-0.55$ to 1.31$)$ \\
\hline
\end{tabular}

* Scheffe post hoc test, significant

(Microsoft Corporation, Bellevue, Washington). All the specimens failed at the site of the tendon-to-bone-tunnel attachment during biomechanical testing.

Statistical analysis. Calculations were made in SPSS version 16.0 for Mac (SPSS Inc., Chicago, Illinois). The results are given as arithmetic means and dispersion as range, confidence intervals $(\mathrm{CI})$ or one SD. The groups were compared using analysis of variance (ANOVA) and Scheffe's post hoc test. The level of significance was set at $\mathrm{p} \leq 0.05$.

\section{Results}

The mean weight of the rats after death was $239 \mathrm{~g}$ (212 to 269) with no significant differences in weight between the groups. A rat from the parecoxib group was killed after a peri-operative fracture of the tibia and one from the indometacin group because of post-operative deep infection. In the control group four rats were killed, two because of infection, one because of a peri-operative fracture of the tibia and one because of post-operative oedema of the leg.

Mechanical testing. We found that there was a significantly lower level of pull-out force ( $p<0.001$, ANOVA), energy absorption ( $\mathrm{p}<0.0001$, ANOVA) and stiffness $(\mathrm{p}=0.035$, ANOVA) in rats given parecoxib and indometacin compared with the control group. There was no difference in deflection (Table I). For all mechanical properties, there was a tendency for greater impairment of the measured effects with parecoxib compared with indometacin.

Calculations of the force needed for pulling out the tendons from the tibia in this model, gave a mean of $3.52 \mathrm{~N}$ in the control group. The force needed in the parecoxib group was $1.71 \mathrm{~N}$, a reduction of $51 \%$ and in the indometacin group $2.25 \mathrm{~N}$, a reduction of $36 \%$. The mean total energy in the control group was $6.46 \mathrm{Nmm}$, in the parecoxib group $2.38 \mathrm{Nmm}$, a reduction of $63 \%$, and in the indometacin group $3.22 \mathrm{Nmm}$, a reduction of $50 \%$. All these reached statistical significance (Table I). The mean stiffness was $1.02 \mathrm{~N} / \mathrm{mm}$ in the control group and $0.63 \mathrm{~N} / \mathrm{mm}$ in the parecoxib group, a reduction of $38 \%$. The mean stiffness in the indometacin group was $0.73 \mathrm{~N} / \mathrm{mm}$, a reduction of $28 \%$. Concerning deflection, the mean in the control group was $3.58 \mathrm{~mm}$, in the parecoxib group $2.93 \mathrm{~mm}$ and in the indometacin group $3.31 \mathrm{~mm}$, a reduction of $18 \%$ and $8 \%$, respectively (Table I).

Parecoxib and indometacin both impaired tendon-tobone healing in a bone tunnel in the rat. In this study a statistical difference between the two medications could not be detected with our numbers of rats (Table II), but there was a trend towards a more pronounced effect with parecoxib compared with indometacin.

\section{Discussion}

Tendons and ligaments may be attached to bone through fibrocartilaginous or fibrous insertions. The latter characteristically occur when tendons and ligaments are attached to diaphyseal bone, and are subdivided into two categories, periosteal and bony. In periosteal insertions, the collagen fibres penetrate the bone indirectly through the periosteum, and in bony insertions they attach directly to the bone without showing fibrocartilage layers. ${ }^{16}$ In fibrocartilaginous insertions, a typical four-layered architecture of tendon, non-mineralised fibrocartilage, mineralised fibrocartilage and bone is seen. ${ }^{17,18}$ Such fibrocartilaginous insertions are present in intact insertions of the ACL on both the tibial and femoral sides. ${ }^{19}$

We are aware of only two previous studies on the effects of cox inhibitors on tendon-to-bone healing. Ferry et $\mathrm{al}^{20}$ demonstrated a detrimental effect on the healing strength and collagen production after injury at the patellartendon-to-bone junction in rats given cox-2 inhibitors, with little or no effect with conventional cox inhibitors. They gave no definite explanation for the difference between the two drugs, but suggested that it may have been due to different absorption and metabolism between them and the uncertainties of oral administration. Cohen et $\mathrm{al}^{21}$ demonstrated in rats that both a conventional cox 
inhibitor and a specific cox-2 inhibitor impaired tendonto-bone healing in the rotator cuff. They cut the intact tendon-to-bone insertion of supraspinatus, debrided all the soft tissues and fibrocartilage from the greater tuberosity and re-approximated the tendon-to-bone to imitate a true rotator-cuff suture. In their histological analysis of the tendon to bone interface, they found fibrocartilaginous healing in the control group, whereas in the coxinhibitor rats the tendinous insertion healed with fibrous tissue only, suggesting that the lack of fibrocartilage layers in the healing ligaments may have been one of the mechanisms interfering with healing. In our study we developed a model to imitate the healing conditions present when reconstructing the ACL with tendon grafts. When implanting a tendon into a bone tunnel, the insertion became composed of fibrous tissue. Collagen fibres from the graft protruded through this directly into the cancellous bone with no fibrocartilaginous element. ${ }^{14,22}$ This finding has also been demonstrated in man when biopsies of the tendon-to-bone insertions have been obtained during revision surgery. The hamstring tendon graft/bonetunnel interface has been shown by Petersen and Laprell ${ }^{23}$ to consist of three distinct histological zones resembling a fibrous tendon insertion.

The initial tendon-to-bone healing is similar to early fracture repair. Since the initial aseptic inflammatory response is necessary to initiate fracture healing, ${ }^{24}$ the same mechanisms are probably present in tendon-to-bone healing. Liu et $\mathrm{al}^{14}$ showed that two weeks after injury the fibrous tissue at the tendon-bone interface included capillary ingrowths, macrophages and a predominantly fibroblastlike cell population.

Kawamura et $\mathrm{al}^{25}$ demonstrated that macrophages accumulated in the early inflammatory phase, and were likely to play an important role in the initiation and regulation of tendon-to-bone healing. Marsolais, Cote and Frenette ${ }^{26}$ showed that a cox inhibitor reduced the accumulation of macrophages in the paratendon but in their model the mechanical properties of the tendons were not affected. This influence on the macrophages could nevertheless affect the initial healing process. Angiogenesis has been shown to be inhibited by cox- 2 inhibitors. ${ }^{27,28}$ Inhibition of angiogenesis may lead to improper delivery of osteoblasts, chondroblasts and fibroblasts to the interface, thereby impairing healing. Thus, inhibition of the initial inflammatory response may be one of the explanations why cox inhibitors also delay tendon-to-bone healing.

Inhibition of the cox-2 enzyme is probably the most important mechanism responsible for the effects of cox inhibitors on fracture healing since it leads to a reduced production of prostaglandins, which are required for inflammation and normal endochondral ossification. ${ }^{11}$ Absence of cox- 2 interferes with the differentiation of mesenchymal cells into the osteoblast lineage. ${ }^{12}$ We have also demonstrated in an earlier study that mineralisation of fracture callus was reduced in rats treated with a cox- 2 inhibitor. ${ }^{29}$
Rodeo et $\mathrm{al}^{22}$ studied tendon healing in a bone tunnel and demonstrated that after four weeks a new lining of the tunnel was present. Prostaglandins enhance bone formation by increasing the replication and differentiation of the osteoblasts $^{30-32}$ and their reduction by cox inhibitors may impair bone formation and interfere with tendon-to-bone healing. It has also been observed that host bone-marrow cells rather than graft cells contribute to the repair of the bone-tendon interface. ${ }^{33}$

There are some obvious limitations and weaknesses in our study. The rats were given a dose of parecoxib equal to human doses, but this may have been too low to secure adequate inhibition of cox- 2 because of the fast metabolism in rats of both celecoxib and rofecoxib. ${ }^{34,35}$ In order to compensate for this, some authors have chosen to administer parecoxib in doses as high as $6.4 \mathrm{mg} / \mathrm{kg}$ daily. ${ }^{36,37}$ However, we have previously demonstrated the inhibiting effects on fracture healing of a dosage of $1.0 \mathrm{mg} / \mathrm{kg}$ of parecoxib daily. ${ }^{29}$ Therefore, we used doses equivalent to those given clinically and to ensure the best possible absorption and sufficient blood concentration, the rats were injected intraperitoneally twice daily. In order to mimic the use of cox-2 inhibitors clinically, the first injection was given immediately before surgery and injections continued twice daily for a week. Although the inhibition of cox-2 administration may have been lower in rats compared with the equivalent dose in patients due to differences in metabolism, we still found large differences in the mechanical properties of the healing tendon grafts. With higher doses of drug the effects may be even more pronounced.

The ideal animal model to simulate an ACL reconstruction with tendon graft should include graft healing in metaphyseal bone in an intra-articular environment. In our model we established the bone tunnel in an extra-articular environment, but still in metaphyseal bone. The tendon was fixed by a periosteal suture only. In a clinical setting ligament repairs or reconstructions would mostly be secured by different types of fixation devices to ensure healing, even though some authors describe suture fixation only. ${ }^{38,39}$ An advantage of our model was that the cyclic loading to the tendon-to-bone complex could be maintained. All the rats were mobilised freely, bearing weight on the operated limb. This may be of importance, acknowledging the deleterious effects of inactivity and immobilisation on uninjured ${ }^{40}$ and injured ${ }^{41}$ ligaments.

The biomechanical testing may also have some limitations when compared with the mechanism of injury in man. The pull-out force in the test was applied slowly and with a constant rate along the axis of the tendon. However, the most common force of injury to the ACL in man is probably a combination of translation and torsion, and initially the speed is higher.

In our study we did not include histological analysis to evaluate the presence or absence of fibrocartilage in the tendon-to-bone interface, but this will be used in future investigations. We chose an early timepoint for mechanical 
testing at two weeks after operation. This point in healing may be crucial in the rehabilitation of patients, since early neuromuscular training after reconstruction of the ACL is important for the clinical outcome. It has been demonstrated that active rehabilitation with open kinetic chain exercises on quadriceps resulted in greater laxity in patients with repairs of the ACL using hamstring tendons. ${ }^{42}$ The use of cox inhibitors may be detrimental to early healing, stability and the eventual function of the knee.

We thank the Department of Comparative Medicine, Rikshospitalet-Radiumhospitalet Medical Centre, University of Oslo, Norway for placing excellent animal facilities and enthusiastic personnel at our disposal.

No benefits in any form have been received or will be received from a commercial party related directly or indirectly to the subject of this article.

\section{References}

1. Granan LP, Bahr R, Steindal K, Furnes 0, Engebretsen L. Development of a national cruciate ligament surgery registry: the Norwegian National Knee Ligament Registry. Am J Sports Med 2008;36:308-15.

2. Goldblatt JP, Fitzsimmons SE, Balk E, Richmond JC. Reconstruction of the anterior cruciate ligament: meta-analysis of patellar tendon versus hamstring tendon autograft. Arthroscopy 2005;21:791-803.

3. Aune AK, Holm I, Risberg MA, Jensen HK, Steen H. Four-strand hamstring tendon autograft compared with patellar tendon-bone autograft for anterior cruciate ligament reconstruction: a randomized study with two-year follow-up. Am J Sports Med 2001;29:722-8

4. Laxdal G, Sernert N, Ejerhed L, Karlsson J, Kartus JT. A prospective comparison of bone-patellar tendon-bone and hamstring tendon grafts for anterior cruciate ligament reconstruction in male patients. Knee Surg Sports Traumatol Arthrosc 2007:15:115-25

5. Fu FH, Bennett CH, Lattermann C, Ma CB. Current trends in anterior cruciate lig ament reconstruction. Part 1: biology and biomechanics of reconstruction. $A m \mathrm{~J}$ Sports Med 1999;27:821-30.

6. Rø J, Sudmann E, Marton PF. Effect of indomethacin on fracture healing in rats. Acta Orthop Scand 1976;47:588-99.

7. Sudmann E, Dregelid E, Bessesen A, Morland J. Inhibition of fracture healing by indomethacin in rats. Eur J Clin Invest 1979;9:333-9.

8. Hogevold HE, Grogaard B, Reikeras $\mathbf{0}$. Effects of short-term treatment with corticosteroids and indomethacin on bone healing: a mechanical study of osteotomies in rats. Acta Orthop Scand 1992;63:607-11.

9. Keller J, Bayer-Kristensen I, Bak B, et al. Indomethacin and bone remodeling: effect on cortical bone after osteotomy in rabbits. Acta Orthop Scand 1989;60:119-21.

10. Engesaeter LB, Sudmann B, Sudmann E. Fracture healing in rats inhibited by locally administered indomethacin. Acta Orthop Scand 1992;63:330-3.

11. Simon AM, Manigrasso MB, O'Connor JP. Cyclo-oxygenase 2 function is essential for bone fracture healing. J Bone Miner Res 2002;17:963-76.

12. Zhang $X$, Schwarz EM, Young DA, et al. Cyclooxygenase-2 regulates mesenchymal cell differentiation into the osteoblast lineage and is critically involved in bone repair. J Clin Invest 2002;109:1405-15.

13. Gerstenfeld LC, Al-Ghawas $\mathbf{M}$, Alkhiary YM, et al. Selective and nonselective cyclooxygenase-2 inhibitors and experimental fracture-healing: reversibility of effects after short-term treatment. J Bone Joint Surg [Am]2007;89-A:114-25.

14. Liu SH, Panossian V, al-Shaikh R, et al. Morphology and matrix composition during early tendon to bone healing. Clin Orthop 1997;339:253-60.

15. Madsen JE, Hukkanen M, Aune AK, et al. Fracture healing and callus innervation after peripheral nerve resection in rats. Clin Orthop 1998;351:230-40.

16. Benjamin M, Kumai T, Milz S, et al. The skeletal attachment of tendons: tendon "entheses". Comp Biochem Physiol A Mol Integr Physiol 2002;133:931-45.

17. Cooper RR, Misol S. Tendon and ligament insertion: a light and electron microscopic study. J Bone Joint Surg [Am]1970;52-A:1-20.
18. Benjamin M, Evans EJ, Copp L. The histology of tendon attachments to bone in man. J Anat 1986;149:89-100.

19. Laros GS, Tipton CM, Cooper RR. Influence of physical activity on ligament insertions in the knees of dogs. J Bone Joint Surg [Am] 1971;53-A:275-86.

20. Ferry ST, Dahners LE, Afshari HM, Weinhold PS. The effects of common antiinflammatory drugs on the healing rat patellar tendon. Am J Sports Med 2007;35:1326-33

21. Cohen DB, Kawamura S, Ehteshami JR, Rodeo SA. Indomethacin and celecoxib impair rotator cuff tendon-to-bone healing. Am J Sports Med 2006;34:362-9.

22. Rodeo SA, Arnoczky SP, Torzilli PA, Hidaka C, Warren RF. Tendon-healing in a bone tunnel: a biomechanical and histological study in the dog. J Bone Joint Surg [Am] 1993;75-A:1795-803.

23. Petersen W, Laprell H. Insertion of autologous tendon grafts to the bone: a histological and immunohistochemical study of hamstring and patellar tendon grafts. Knee Surg Sports Traumatol Arthrosc 2008;8:26-31.

24. Simmons DJ. Fracture healing perspectives. Clin Orthop 1985;200:100-13.

25. Kawamura S, Ying L, Kim HJ, Dynbil C, Rodeo SA. Macrophages accumulate in the early phase of tendon-bone healing. J Orthop Res 2005;23:1425-32.

26. Marsolais D, Cote CH, Frenette J. Nonsteroidal anti-inflammatory drug reduces neutrophil and macrophage accumulation but does not improve tendon regeneration. Lab Invest 2003;83:991-9.

27. Jones MK, Wang H, Peskar BM, et al. Inhibition of angiogenesis by nonsteroidal anti-inflammatory drugs: insight into mechanisms and implications for cancer growth and ulcer healing. Nat Med 1999;5:1418-23.

28. Schmassmann A, Peskar BM, Stettler C, et al. Effects of inhibition of prostaglandin endoperoxide synthase-2 in chronic gastro-intestinal ulcer models in rats. $\mathrm{Br} \mathrm{J}$ Pharmacol 1998;123:795-804.

29. Dimmen S, Nordsletten L, Engebretsen L, Steem H, Madsen JE. Negative effect of parecoxib on bone mineral during fracture healing: a study in rats. Acta Orthop 2008;79:438-44.

30. Lin CH, Jee WS, May YF, Setterberg RB. Early effects of prostaglandin E2 on bone formation and resorption in different bone sites of rats. Bone 1995;17(4 Suppl):255-9.

31. Jee WS, Ueno K, Kimmel DB, et al. The role of bone cells in increasing metaphyseal hard tissue in rapidly growing rats treated with prostaglandin E2. Bone 1987;8:171-8.

32. Nefussi JR, Baron R. PGE2 stimulates both resorption and formation of bone in vivo: differential responses of the periosteum and the endosteum in fetal rat long bone cultures. Anat Rec 1985;211:9-16.

33. Kobayashi M, Watanabe $\mathbf{N}, \mathbf{O}$ shima $\mathbf{Y}$, et al. The fate of host and graft cells in early healing of bone tunnel after tendon graft. Am J Sports Med 2005;33:1892-7.

34. Halpin RA, Geer LA, Zhang KE, et al. The absorption, distribution, metabolism and excretion of rofecoxib, a potent and selective cyclooxygenase- 2 inhibitor, in rats and dogs. Drug Metab Dispos 2000;28:1244-54

35. Paulson SK, Zhang JY, Breau AP, et al. Pharmokinetics, tissue distribution, metabolism, and excretion of celecoxib in rats. Drug Metab Dispos 2000;28:514-21.

36. Meunier A, Aspenberg P. Parecoxib impairs early metaphyseal bone healing in rats. Arch Orthop Trauma Surg 2006;126:433-6.

37. Virchenko 0, Skoglund B, Aspenberg P. Parecoxib impairs early tendon repair but improves later remodeling. Am J Sports Med 2004;32:1743-7.

38. LaPrade RF, Hilger B. Coracoclavicular ligament reconstruction using a semitendinosus graft for failed acromioclavicular separation surgery. Arthroscopy 2005;21:1277.

39. Ellera Gomes JL, Stigler Marczyk LR, Cesar de Cesar P, Jungblut CF. Media patellofemoral ligament reconstruction with semitendinosus autograft for chronic patellar instability: a follow-up study. Arthroscopy 2004;20:147-51.

40. Noyes FR, Torvik PJ, Hyde WB, DeLucas JL. Biomechanics of ligament failure. II. an analysis of immobilization, exercise, and reconditioning effects in primates. J Bone Joint Surg [Am] 1974;56-A:1406-18

41. Hart DP, Dahners LE. Healing of the medial collateral ligament in rats: the effects of repair, motion, and secondary stabilizing ligaments. J Bone Joint Surg [Am] 1987;69A:1194-9.

42. Heijne A, Werner S. Early versus late start of open kinetic chain quadriceps exercises after ACL reconstruction with patellar tendon or hamstring grafts: a prospective randomized outcome study. Knee Surg Sports Traumatol Arthrosc 2007;15:402-14. 